\title{
PERANCANGAN SISTEM INFORMASI PKL DAN SKRIPSI YANG MAMPU MENGUKUR WAKTU PENYELESAIAN PENGAJUAN SURAT TUGAS PEMBIMBING
}

\author{
Donny Montreano \\ Program Studi Teknik Industri, Fakultas Teknik \\ Universitas Pembangunan Nasional “Veteran” Jakarta \\ JL. RS Fatmawati - Pondok Labu Jakarta Selatan 12450, Indonesia, Telp.021-7856971 \\ Email : montreano@gmail.com
}

\begin{abstract}
Computerized information system is neededs to help the Dikjar Unit to ease business processes at Faculty of Engineering, Universitas Pembangunan Nasional "Veteran" Jakarta to input data. Therefore, it is necessary to design information systems that can support the process. As for tools and construction techniques used in this design, such as flowchart, data flow diagram (DFD) and Entity Relationship Diagram (ERD). And use of software, such as Microsoft Visual Basic 2013 as a tool for designing programs based on web, Microsoft Excel 2013 as the database that will connect with the program designed. This research was limited to only discussing about the design and internal running test. The real appliying on the Dikjar Unit will be discuss on next period of this jurnal. The end result of this research is a web-based application program that used to perform data entry preceptor of thesis and work practice, which are able to assess the performance of the Dikjar's Unit completion time.
\end{abstract}

Keywords : internship database, performance assessment, SIM, Web Application

\section{PENDAHULUAN}

\section{Latar Belakang}

Mulai dari tahun 2008, jumlah mahasiswa di fakultas teknik Universitas Pembangunan Nasional "Veteran" Jakarta, atau disingkat UPNVJ, menampakkan peningkatan yang bergerak perlahan tapi pasti dibanding tahuntahun sebelumnya. Peningkatan yang sangat signifikan terjadi tahun 2014 sampai sekarang dengan rata-rata per angkatan lebih dari 90 orang. Puncak jumlah mahasiswa terjadi di jurusan Teknik Mesin sebanyak 70 Orang pada tahun ini. Jumlah yang sedemikian besar tentu akan mempengaruhi kinerja di beberapa unit kerja fakultas teknik seperti unit Kemahasiswaan, unit Dikjar, unit PPK, unit Sarpras, Unit Laboratorium dll. Unit-unit tersebut yang berhubungan langsung dengan mahasiswa adalah unit Dikjar dan Unit Kemahasiswaan. Kedua unit tersebut melayani berkas salah satunya ialah form pengajuan PKL dan Form pengajuan skripsi.

Permintaan PKL, pengumpulan laporan PKL dan Skripsi adalah tugas wajib bagi seluruh mahasiswa jenjang strata satu (S-1) di Fakultas Teknik UPNVJ. Laporan PKL dan Skripsi merupakan satu kesatuan kurikulum pendidikan yang harus ditempuh oleh semua mahasiswa sebagai kegiatan yang bersifat wajib dan sebagai syarat kelulusan.

Data PKL dan Skripsi yang di masukkan terdiri dari, nama, nim, jurusan, topik laporan, nama perusahaan, nama pembimbing, jadwal sidang, dan seterusnya. Tiap-tiap mahasiswa wajib mengisi data tersebut di form pengajuan lalu form itu diberikan ke operator Dikjar. Lalu operator mengetiknya lagi di komputer agar sesuai format yang berlaku.

Dalam pemasukkan data inilah sering kali terjadi kesalahan baik dalam pengetikan maupun tertukarnya data-data oleh operator Dikjar. Dan pengadaan data tidak selesai dalam kurun waktu yang singkat dikarenakan hanya ada satu operator yang bekerja untuk melayani kurang lebih 500 mahasiswa yang melakukan permintaan penginputan dalam kebutuhan akademik termasuk sebagian di dalamnya PKL dan Skripsi.

Sistem Informasi Manajemen untuk pemasukkan data penunjang PKL dan skripsi bertujuan untuk menyediakan sebuah program aplikasi berbasis desktop yang dapat membantu Kasubag Dikjar dalam penginputan data PKL dan Skripsi secara kompleks / terperinci. Penilaian kinerja Kasubag Dikjar juga perlu diadakan untuk dapat mengevaluasi kinerja Kasubag Dikjar dalam melayani mahasiswa dalam bidangnya. Diharapkan dalam evaluasi ini dapat memberikan pertimbangan untuk menambah operator.

Proses pengolahan dan pembuatan sistem informasi ini menggunakan software Visual Studio 2013 dan Microsoft Excel 2013 


\section{Rumusan Masalah}

Dalam penginputan data PKL dan Skripsi sering memakan waktu terlalu lama, seringkali karena salah huruf, salah tempat dan mencari - cari data. Jika terjadi kesalahan maka baik dosen maupun mahasiswa harus bolak-balik untuk mencetakknya kembali di tempat Dikjar. Aktifitas itu menjadi sebab lambannya penyelesaian di unit kerja selanjutannya. Hal tersebut secara tidak langsung merugikan mahasiswa yang membutuhkan waktu lulus lebih cepat juga membutuhkan proses kuliah dengan nyaman tanpa gangguan administratif karena gangguan ini dapat menurunkan semangat mahasiswa. Sehingga sangatlah penting untuk diadakannya sistem informasi untuk membantu mengurangi waktu proses bisnis Kasubag Dikjar.

\section{Tujuan Penelitian}

Adapun tujuan dari penelitan ini adalah merancang sistem informasi tipe web application untuk pemasukkan data pengajuan pembimbing PKL dan Skripsi yang kemudian di unggah ke website resmi fakultas.

\section{TINJAUAN PUSTAKA}

\section{Sistem Informasi}

Sistem informasi adalah suatu sistem yang mampu menyediakan informasi yang bermanfaat bagi penggunanya, atau suatu sistem terintegrasi atau sistem manusia-mesin untuk menyediakan informasi untuk mendukung operasi, manajemen dalam suatu organisasi. Sistem yang dimaksud ini memanfaatkan perangkat keras dan perangkat lunak komputer, prosedur manual, model manajemen dan basis data.

\section{Tujuan Sistem Informasi Manajemen}

Tujuan sistem informasi manajemen adalah memenuhi kebutuhan informasi umum semua manajer dalam perusahaan atau dalam subunit organisasional perusahaan. SIM menyediakan informasi bagi pemakai dalam bentuk laporan dan output dari berbagai simulasi model matematika.

\section{Alat Bantu Perancangan Sistem Informasi}

Analisis data masukan adalah suatu analisis yang dilakukan terhadap data-data dari entitas luar yang dimasukkan kedalam sistem. Dengan tujuan untuk mendapatkan pemahaman sistem secara keseluruhan, tentang sistem yang berjalan sekarang sehingga permasalahan dapat dipecahkan dan kebutuhan pemakai sistem dapat di identifikasi dengan benar. Pada tahapan analisis ini menggunakan beberapa alat bantu untuk dapat menggambarkan sistem secara keseluruhan. Alat bantu yang digunakan adalah Flowchart, Diagram Konteks, DFD (Data Flow Diagram) dan ERD (Entity Relationship Diagram).

\section{Flowchart (Bagan Alir)}

Bagan alir (flowchart) adalah bentuk grafik atau diagram dari algoritma dimana simbol simbol standar mewakili tampilan operasi yang perlu dan memperlihatkan urutan pelaksanaannya serta berisikan mengenai langkah kegiatan pencatatan, penganalisisan, dan pengkoordinasian informasi. Pada bagan alir proses kegiatan beserta langkah - langkah dan urutannya dapat digambarkan dengan cara yang lebih mudah dan jelas.

\section{Diagram Konteks}

Diagram konteks adalah diagram yang mencakup masukan-masukan dasar, sistem umum dan keluaran, diagram ini merupakan tingkatan tertinggi dalam diagram aliran data dan hanya memuat satu proses, menunjukan sistem secara keseluruhan, diagram tersebut tidak memuat penyimpanan dan penggambaran aliran data yang sederhana, proses tersebut diberi nomor nol. Semua entitas ekternal yang ditunjukan pada diagram konteks berikut aliran data-aliran data utama menuju dan dari sistem.

\section{Data Flow Diagram (DFD)}

DFD merupakan gambaran suatu sistem yang telah ada atau sistem baru yang dikembangkan secara logika tanpa mempertimbangkan lingkungan fisik dimana data tersebut mengalir. Dengan adanya data flow diagram maka pemakai sistem yang kurang memahami dibidang komputer dapat mengerti sistem yang sedang berjalan.

\section{Entity Relationship Diagram (ERD)}

ERD adalah model konseptual yang mendeskripsikan hubungan antara penyimpanan (dalam DFD). ERD digunakan untuk memodelkan struktur data dan hubungan antar data. Dengan ERD, model dapat diuji dengan mengabaikan proses yang dilakukan. ERD pertama kali dideskripsikan oleh Peter Chen yang dibuat sebagai bagian dari perangkat lunak CASE.

\section{Perangkat Lunak Pendukung}

Dalam pembuatan sebuah sistem informasi ini digunakan beberapa perangkat lunak pendukung seperti :
a. Microsoft Visual Basic.Net 2013
b. Microsoft Excel 2013

\section{Uji Kecukupan Data}

$$
N^{\prime}=\left(\frac{\frac{k}{s} \sqrt{N . \Sigma X i^{2}-(\Sigma X i)^{2}}}{\Sigma X i}\right)
$$

Dimana:

N' = Jumlah Pengamatan yang seharusnya dilakukan. 
$\mathrm{K}=$ Tingkat kepercayaan dalam pengamatan. Jika tingkat keyakinan $99 \%$ maka $\mathrm{k}=2,58 \approx 3$ Jika tingkat keyakinan $95 \%$ maka $\mathrm{k}=1,96 \approx 2$ Jika tingkat keyakinan $68 \%$ maka $\mathrm{k} \approx 1$ $\mathrm{s}=$ Derajat ketelitian dalam pengamatan. Jika tingkat keyakinan 99\% maka s $=1 \%$ Jika tingkat keyakinan 95\% maka s $=5 \%$ $\mathrm{N}=$ Jumlah Pengamatan yang sudah dilakukan. $\mathrm{Xi}=$ Data Pengamatan.

Jika $\mathrm{N} \geq \mathrm{N}$ ' maka dapat dinyatakan bahwa data sudah cukup.

\section{Uji t - test dependent (Paired t-test)}

Uji beda rata-rata dikenal juga dengan nama uji-t (t-test). Konsep dari uji beda rata - rata adalah membandingkan nilai rata-rata beserta selang kepercayaan tertentu (confidence interval) dari dua populasi.

Berikut adalah rumus yang digunakan :

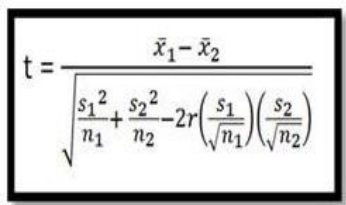

\section{KETERANGAN:}

$\bar{x}_{1}=$ Rata-rata sampel 1

$\bar{x}_{2}=$ Rata-rata sampel 2

$s_{1}=$ Simpangan baku sampel 1

$s_{2}=$ Simpangan baku sampel 2

$s_{1}^{2}=$ Varians sampel 1

$s_{2}{ }^{2}=$ Varians sampel 2

$r=$ Korelasi antara dua sampel

\section{METODE PENELITIAN}

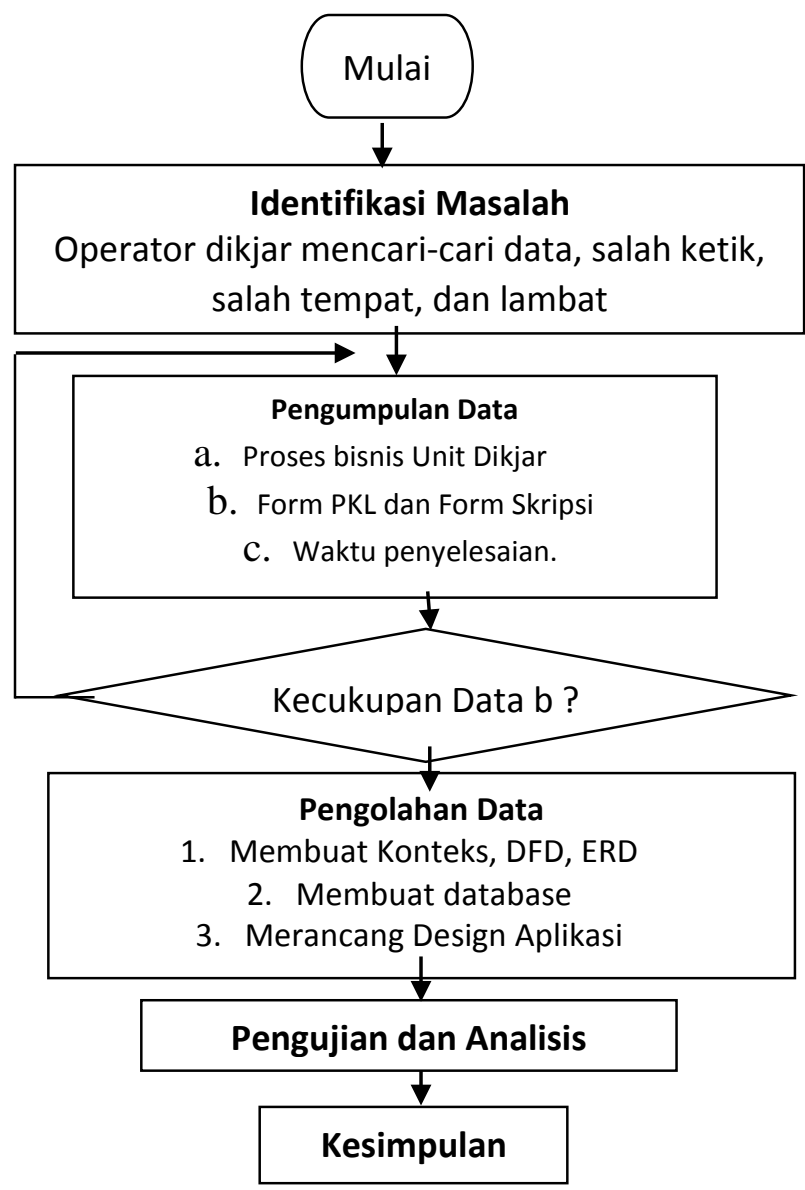

Gambar 1 Flowchart Penelitian

\section{HASIL DAN PEMBAHASAN Pengumpulan Data}

Berikut adalah proses bisnis Satker Dikjar yang dijelaskan dalam bentuk diagram alir.

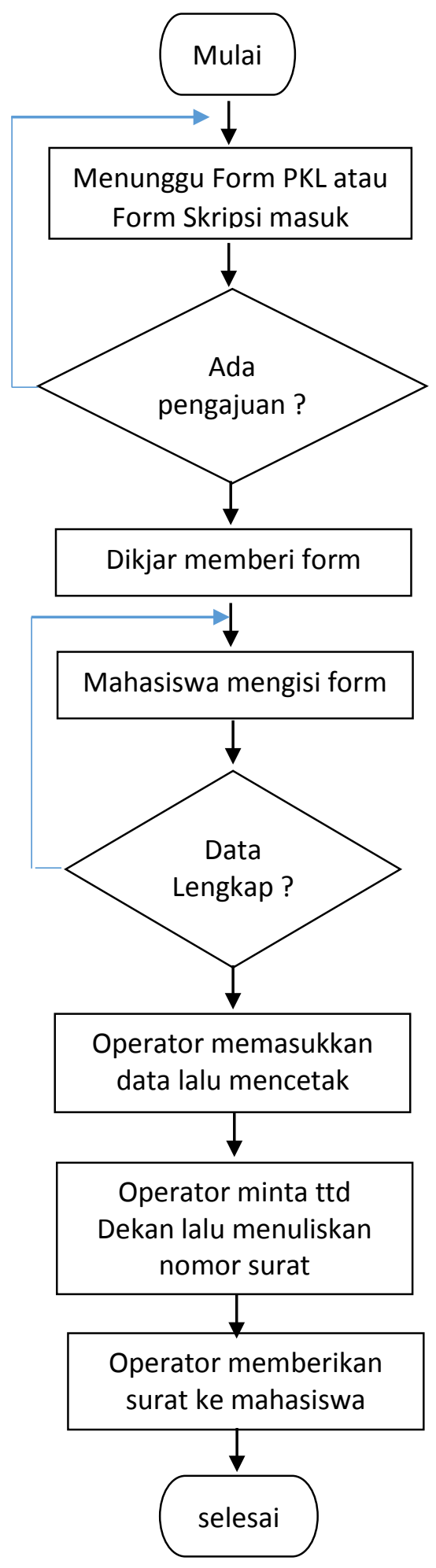

Gambar 2 Proses Bisnis PKL / Skripsi

Form pengajuan PKL dan pengajuan Skripsi dapat dilihat di ft.upnvj.ac.id

Berikut di bawah ini adalah waktu dalam satuan menit yang digunakan operator untuk 
memasukkan data dari form pengajuan seperti gambar 10. Pengambilan data mulai dilakukan hanya pada saat operator memasukkan data sampai operator mencetaknya.

\section{Tabel 1 Completion Time Sebelum dan Sesudah} Penerapan Software

\begin{tabular}{|cl|}
\hline Sample & menit \\
2 & 1.31 \\
2 & 1.53 \\
3 & 1.51 \\
4 & 1.59 \\
5 & 1.42 \\
6 & 2.1 \\
7 & 2.02 \\
8 & 2.26 \\
9 & 2.06 \\
10 & 2.11 \\
\hline
\end{tabular}

\section{Usulan Proses Bisnis}

Di bawah ini adalah usulan proses bisnis kepada Satker Dikjar yang dijelaskan dalam gambar 3 diagram konteks.

Gambar tersebut di atas merupakan proses bisnis secara umum dan tidak menunjukkan dimana proses awal dan akhir, karena beberapa arus data tidak dicantumkan didalamnya seperti informasi rata-rata waktu yang dihabiskan untuk menyelesaikan proses pengajuan, data statistik tentang topik-topik pengajuan, dan status pengajuan. Namun informasi-informasi tersebut dapat saja ditambahkan ke dalam gambar 4 Data Flow Diagram dibawah.

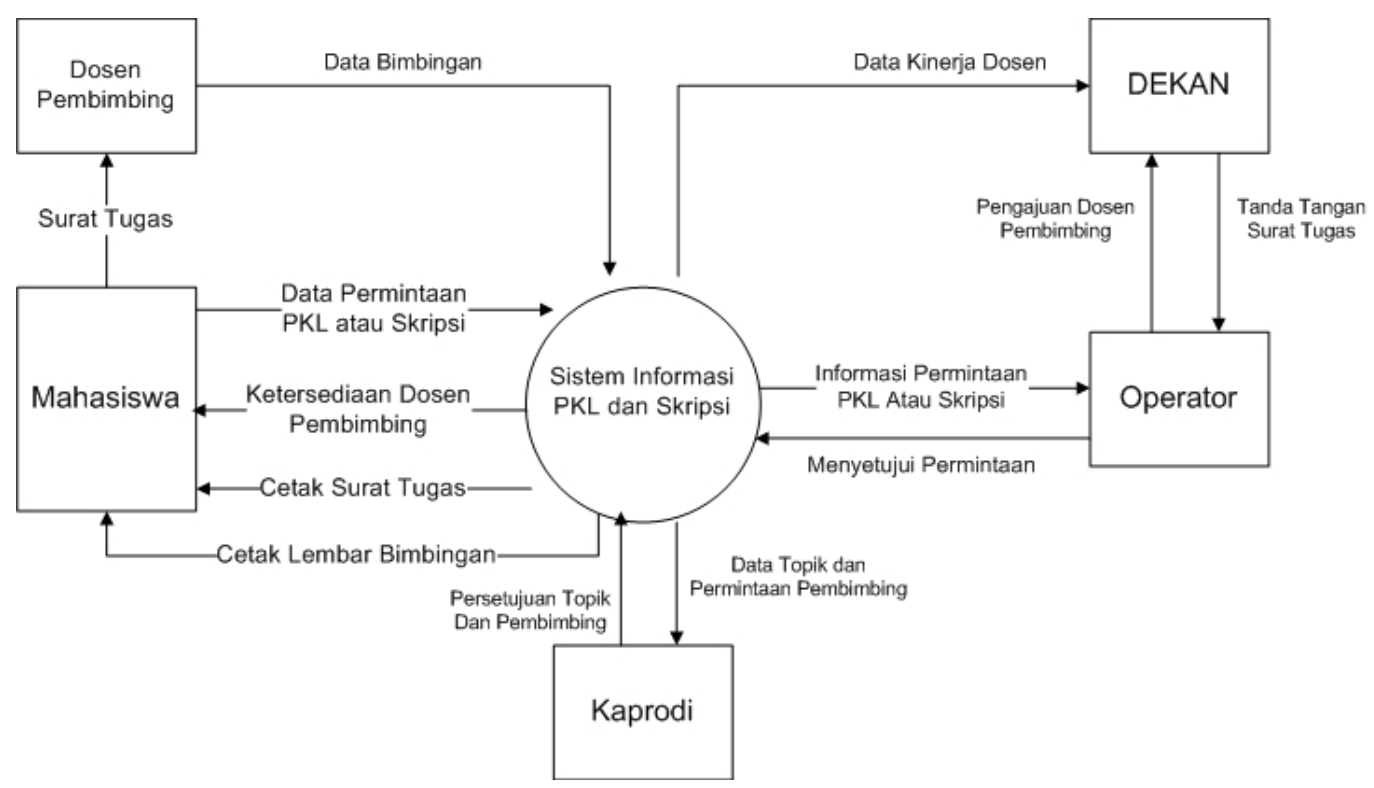

Gambar 3 Diagram Konteks Proses Bisnis

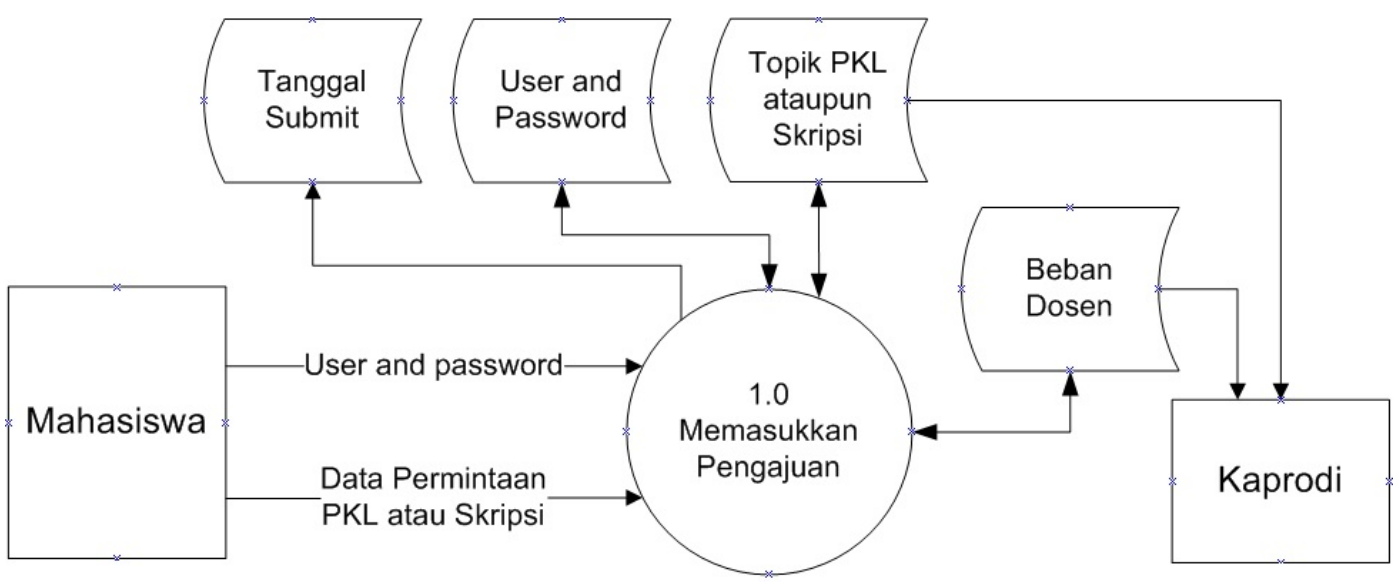

Gambar 4 Data Flow Diagram Level 1 Proses 1 


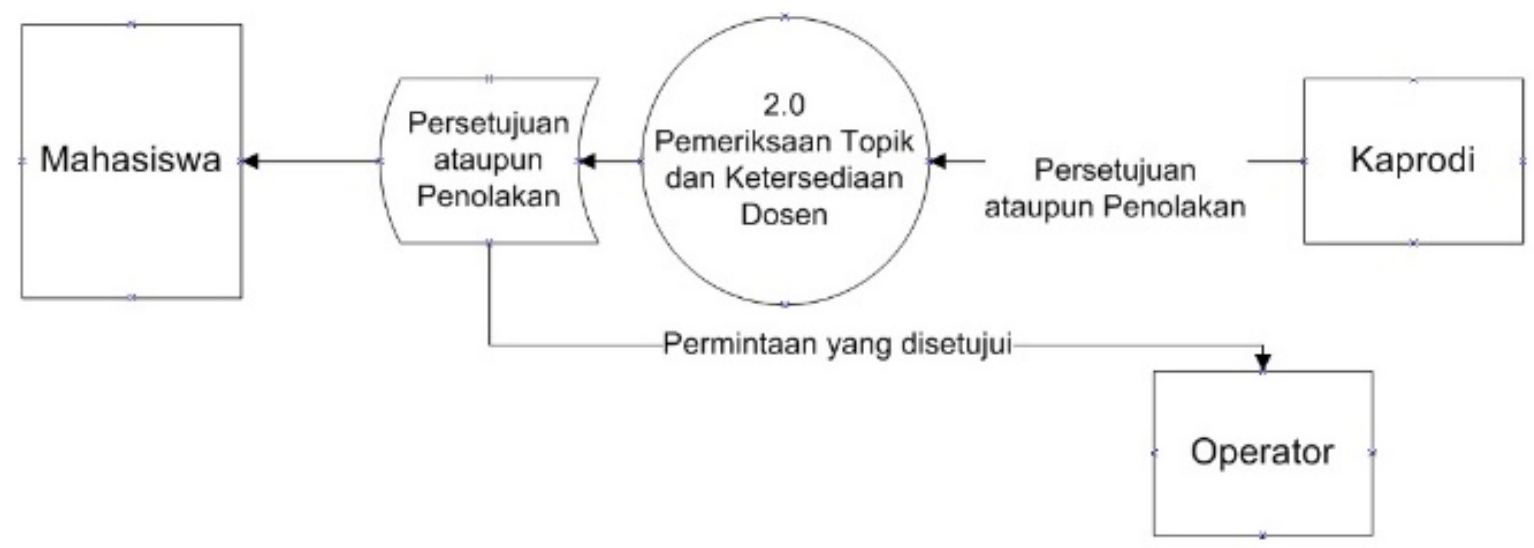

Gambar 6 Data Flow Diagram Level 1 Proses 3

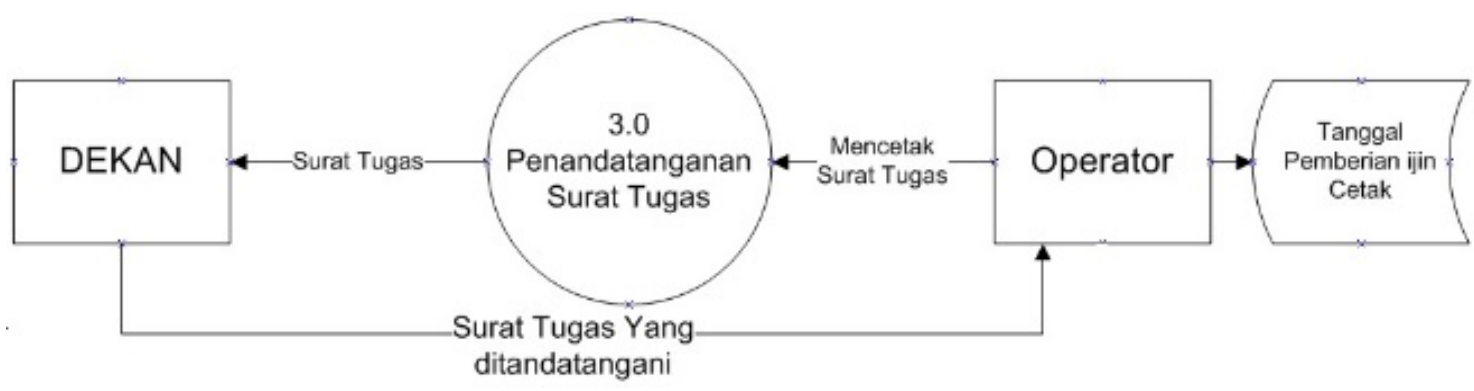

Gambar 5 Data Flow Diagram Level 1 Proses 2

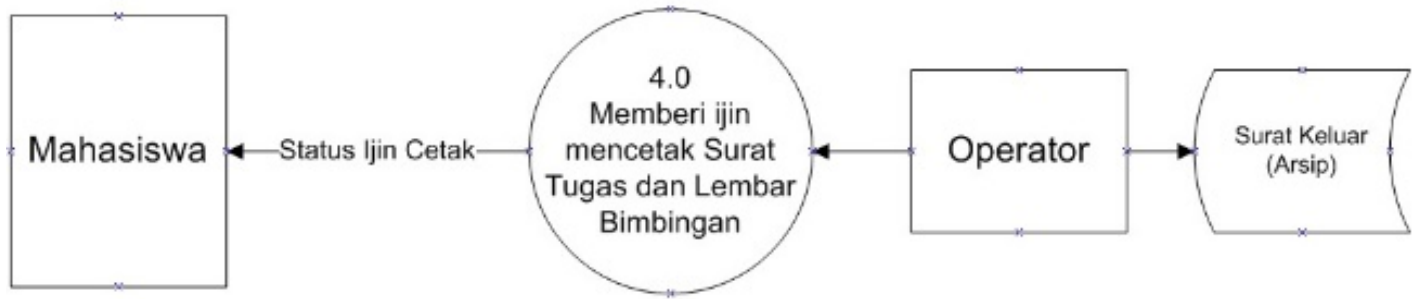

Gambar 7 Data Flow Diagram Level 1 Proses 4

Perbedaan yang signifikan pada proses di atas adalah mahasiswa tidak perlu berhadapan langsung dengan operator. Mahasiswa mengawali dan mengakhiri proses permintaan PKL atau Skripsi cukup dari layar komputer. Kesamaannya adalah mahasiswa tetap harus menemui Kaprodi untuk konsultasi topik.

\section{Mulai Menghitung Waktu}

Proses di awali dengan membuka website ft.upnvj.ac.id, lalu mengisi username dan password lalu tekan login. Penghitungan waktu layanan dimulai sejak mahasiswa tekan tombol submit setelah selesai mengisi data yang diperlukan untuk pengajuan. Setelah itu mahasiswa menunggu status permintaannya yang akan diproses. Website akan memberi tahu dengan alarm kepada kaprodi bahwa ada permintaan datang. Jika kaprodi setuju maka klik setuju. Setelah itu, informasi tersebut dikirim ke
Dikjar dengan alarm dilayar dan operator harus mencetak surat tugas lalu meminta dekan untuk menandatangani. Dekan dapat melihat beban kinerja dosen di halaman website tersebut.

Setelah surat ditandatangani dekan, selanjutnya operator menyimpannya ke arsip fakultas sebagai surat keluar, dan operator harus menekan tombol approve di website untuk memberitahu mahasiswa agar mencetak surat itu dan memberikannya kepada Dosen Pembimbing.

\section{Entity Relationship Diagram}

Entiti membawa serta atribut-atributnya untuk disimpan dalam file. Entitas yang tidak memiliki data untuk disimpan, tidak perlu ditulis dalam gambar ERD. Oleh sebab itu entitas terdiri dari mahasiswa PKL Kaprodi, operator dan dosen pembimbing. 


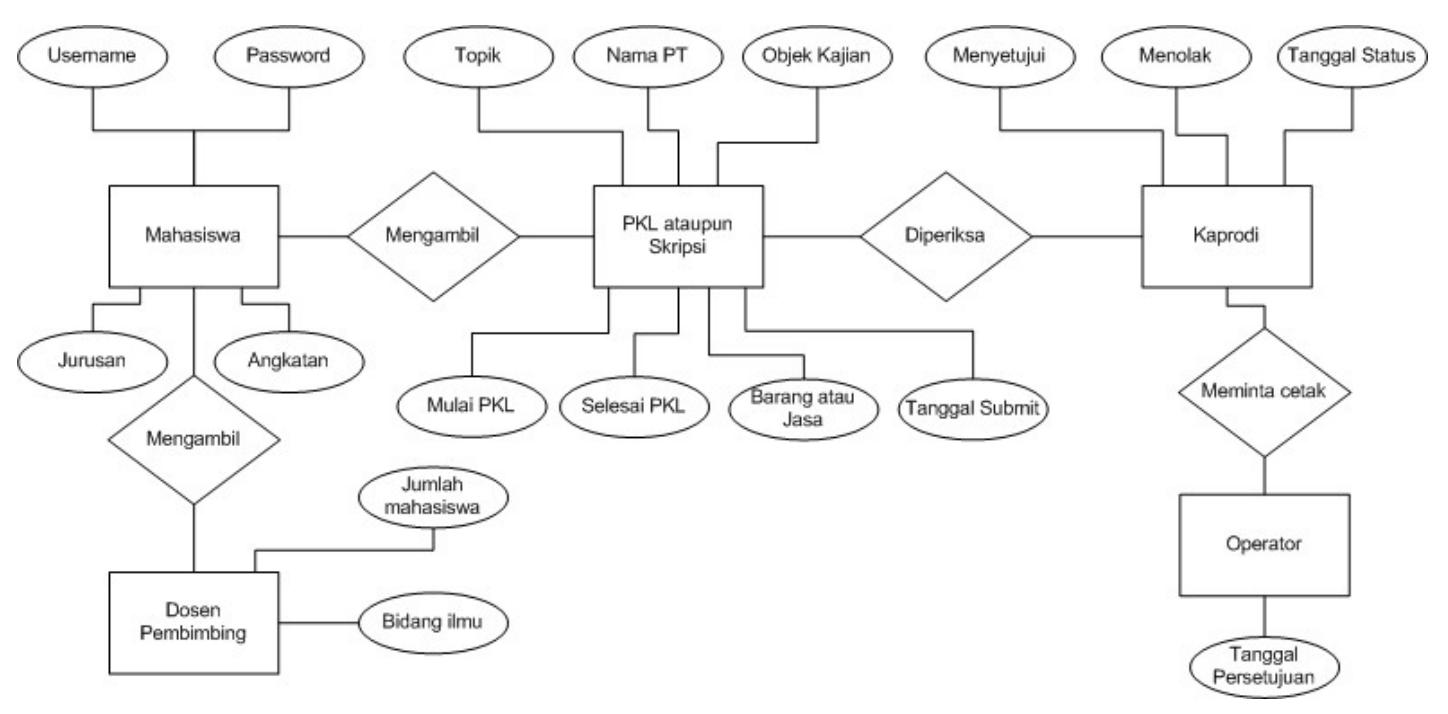

Gambar 8 Entity Relationship Diagram

Entity PKL menjadi enititas yang paling banyak memiliki atribut, yaitu 7. Hal tersebut diperlukan agar tidak mengalami duplikasi judul PKL. Namun topik dan Nama PT boleh sama asalkan objek kajian berbeda. Entity operator memiliki atribut paling sedikit karena hanya untuk kebutuhan pengukuran waktu. Jika fakultas memiliki 1000 mahasiswa maka atribut operator dapat bertambah seperti atribut nama dan password.

\section{Rancangan Input User Interface}

Rancangan yang pertama adalah untuk mahasiswa melakukan login seperti gambar 9 disamping. Setelah submit berhasil, maka lanjut ke form pengajuan PKL atau Skripsi, seperti gambar 10.

Rancangan gambar 10 ini berdasar form pengajuan PKL dan Skripsi yang telah resmi beredar namun sedikit dirubah khusus hanya menghapus bagian tanda tangan Kaprodi dan Pemohon. Sebagai gantinya, Kaprodi hanya mengklik tombol pada gambar 10 dibawah ini. Kaprodi dapat menolak dengan suatu alasan misalnya beban dosen pembimbing sudah maksimal, kompetensi dosen tidak cocok dengan topik
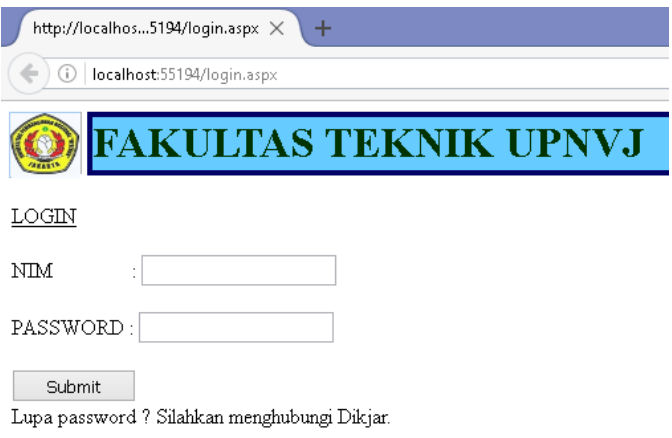

Gambar 9 Form Login Mahasiswa terdapat duplikasi dengan yang lain, dan sebagainya. Setelah Kaprodi tekan tombol menyetujui maka informasi dikirim ke layar Dikjar.

Persetujuan dari Kaprodi akan memunculkan MessageBox ke layar Dikjar agar segera mencetak dan meminta tanda tangan dekan. Tampilan layar Dikjar sama persis dengan surat tugas yang telah resmi beredar di FT dan tampilan dilayarnya diberi dua tombol. Tombol pertama dengan tulisan "cetak" dan tombol kedua dengan tulisan "informasikan ke mahasiswa" seperti gambar 11. Jika surat tugas telah ditanda tangani dekan maka Dikjar menekan tombol kedua. Saat itulah pengukuran waktu berhenti lalu disimpan dalam database penyelesaian kerja.

Waktu yang dibutuhkan untuk menyelesaikan permintaan PKL atau Skripsi dapat dilihat oleh mahasiswa, Kaprodi, maupun Dikjar di layar masing-masing dengan ciri huruf bold.

\section{Database Excel}

File excel yang dipakai untuk menyimpan data diubah menjadi Shared Workbook yang artinya file tersebut dapat digunakan dengan user lain secara bersama sama. Cara merubahnya ialah klik Review Tab lalu klik Share Workbook.

Pengujian penggunaan database excel masih dalam tahap intranet atau dengan kata lain penerapan di jaringan dalam 2 client yang dihubungkan access point. Namun demikian sukses menyimpan data di file yang diletakkan di salah satu client. 
http://localhos...94/Default.aspx $\times+$

localhost:55194/Defaultaspx

INDUSTRIAL ENGINEERING

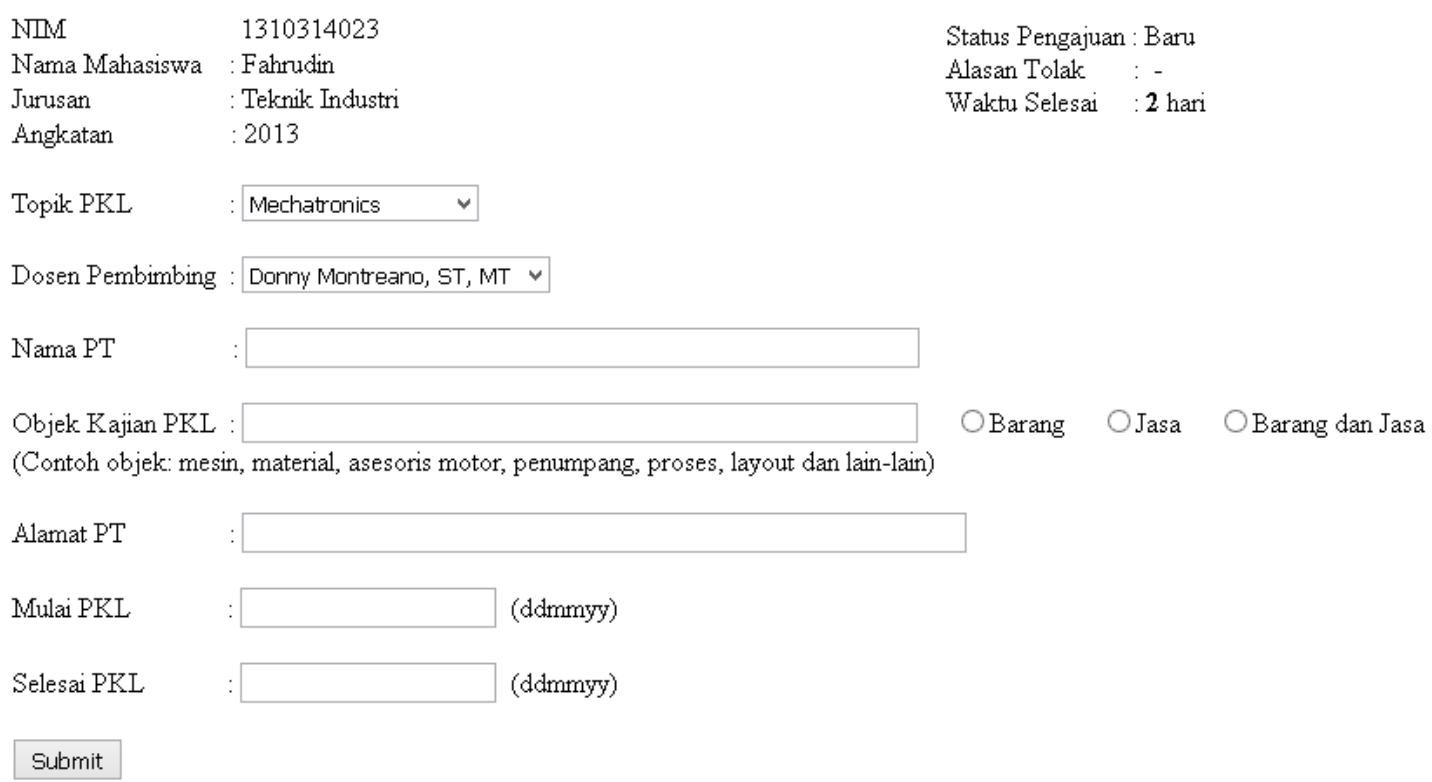

Gambar 10 Form Data PKL

\section{Kelemahan Database Excel}

Ada 4 kelemahan yang masih tahap penyelesaian yaitu:

1. Client harus sudah menginstal Microsoft Excel terbaru

2. Tidak dapat menyimpan data secara bersamaan, salah satu pemakai harus mengalah. Tetapi hal ini dapat diselesaikan dengan menambahkan kode yang mengatur urutan simpan.

3. Tidak dapat autofill. Tetapi hal ini dapat diselesaikan dengan menambahkan kode pemrograman yang berfungsi mencari.

4. Program tidak berjalan ketika Microsoft Excel di uninstall.

\section{Analisis Penilaian Kinerja Operator}

Berdasarkan perhitungan waktu yang digunakan dalam penginputan form pengajuan dosen pembimbing PKL dan Skripsi didapatkan hasil bahwa rata-rata kinerja operator dalam penginputan menggunakan program adalah baik. Penetapan waktu per input satu dokumen adalah selama 1,11 menit sedangkan rata-rata penilaian kinerja operator dalam menginput menggunakan program dalam menginput data PKL dan Skripsi berturut adalah 1,06 menit dan 1,02 menit.

\section{Analisis Uji t-test dependent (Paired t-test)}

$\mathrm{H}_{0}=$ Rata-rata waktu penginputan data sebelum menggunakan program lebih rendah atau sama dengan rata-rata penginputan setelah menggunakan program. $\mathrm{H}_{1}=$ Rata-rata waktu

\section{Tabel 3 Perhitungan Paired t-test}

\begin{tabular}{|c|c|c|}
\hline \multicolumn{3}{|c|}{ t-Test: Paired Two Sample for Means } \\
\hline & Sebelum & Sesudah \\
\hline Mean & 1,791 & 0,92 \\
\hline Variance & 0,122054444 & 0,078733333 \\
\hline Observations & 10 & 10 \\
\hline Pearson Correlation & $-0,188038924$ & \\
\hline Hypothesized Mean Difference & 0 & \\
\hline df & 9 & \\
\hline t Stat & 5,649957549 & \\
\hline Sig one-tail & 0,000156809 & \\
\hline t Critical one-tail & 1,833112933 & \\
\hline Sig two-tail & 0,000313618 & \\
\hline t Critical two-tail & 2,262157163 & \\
\hline
\end{tabular}

penginputan data sebelum menggunakan program lebih tinggi daripada rata-rata waktu penginputan setelah menggunakan program. $\alpha=$ 95\% Tabel 3 Perhitungan Paired t-test Dari perhitungan didapatkan nilai signifikasi one tail sebesar $0,0001<\alpha$ sebesar 0,05, maka H0 ditolak atau $\mathrm{H}_{1}$ diterima sehingga dapat 
disimpulkan bahwa rata-rata waktu penginputan data sebelum menggunakan program lebih tinggi daripada rata-rata waktu penginputan setelah menggunakan program.

\section{SIMPULAN}

Database berbasis excel masih belum bisa digunakan di jaringan yang lebih luas seperti jaringan internet karena database ini menuntut pengguna untuk terlebih dahulu menginstall Microsoft Excel. Sehingga akan merepotkan mahasiswa yang belum tentu mampu menginstal software tersebut apalagi memiliki komputer.

Solusi sementara adalah mahasiswa tetap kekampus untuk mengisi form PKL ataupun skripsi di komputer yang disediakan fakultas. Kehadiran mahasiswa tersebut juga sejalan dengan kebutuhan konsultasi topik dengan Kaprodi di fakultas.

Penggunaan program khusus data PKL maupun skripsi yang diwakili operator terbukti mengurangi waktu penginputan data meskipun perbedaan sangat tipis.

\section{SARAN}

Penelitian selanjutnya memerlukan waktu yang banyak untuk mengumpulkan data dari puluhan mahasiswa sehingga aplikasi dapat menghitung rata-rata waktu permintaan.

Aplikasi juga perlu ditambahkan tampilan kecukupan data agar informasi ratarata pemakaian waktu dapat dinyatakan valid.
Dasar Komputer dan Pemrograman Visual Basic 2013, FT UPNVJ, Jakarta

6. Zain, Ilham, Paired t test : diakses 24 Juli 2016,https://www.youtube.com/watch? time_continue $=361 \& v=x E w p W \_o h U Z s$

\section{DAFTAR PUSTAKA}

1. Jogiyanto, H.M., 2005, Analisa dan Desain Sistem Informasi: Pendekatan Terstruktur Teori dan Praktik Aplikasi Bisnis, ANDI, Yogyakarta

2. https://fairuzelsaid.wordpress.com/2010/ 03/16/sistem-basis-data-entity-relationship -diagram-erd/

3. https://www.tutorialspoint.com/dbms/er_ diagram_representation.htm

4. https://msdn.microsoft.com/en-us/library/ aa286485.aspx

5. Montreano, D., 2016, Modul Praktikum 